\title{
Factors that influence elastomeric coating performance: the effect of coating thickness on basal plate morphology, growth and critical removal stress of the barnacle Balanus amphitrite
}

\author{
D. E. WENDT ${ }^{1}$, G. L. KOWALKE ${ }^{1}$, J. $\mathrm{KIM}^{2}$ \& I. L. SINGER ${ }^{2}$ \\ ${ }^{1}$ Biological Sciences Department and Center for Coastal Marine Science, California Polytechnic State University, San Luis \\ Obispo and ${ }^{2}$ Code 6176 US Naval Research Laboratory, Washington, DC, USA
}

\begin{abstract}
Silicone coatings are currently the most effective non-toxic fouling release surfaces. Understanding the mechanisms that contribute to the performance of silicone coatings is necessary to further improve their design. The objective of this study was to examine the effect of coating thickness on basal plate morphology, growth, and critical removal stress of the barnacle Balanus amphitrite. Barnacles were grown on silicone coatings of three thicknesses (0.2, 0.5 and 2 mm). Atypical ("cupped") basal plate morphology was observed on all surfaces, although there was no relationship between coating thickness and i) the proportion of individuals with the atypical morphology, or ii) the growth rate of individuals. Critical removal stress was inversely proportional to coating thickness. Furthermore, individuals with atypical basal plate morphology had a significantly lower critical removal stress than individuals with the typical ("flat") morphology. The data demonstrate that coating thickness is a fundamental factor governing removal of barnacles from silicone coatings.
\end{abstract}

\section{Introduction}

There has been considerable effort over the past 25 years to develop non-toxic, foul-release coatings to aid in the control and prevention of biofouling (Swain, 2004). This effort has been driven mainly by environmental regulations that have reduced or in some cases eliminated the use of highly effective toxic paints (e.g. triorganotin-based paints) (Walker, 1998). In contrast to toxic paints, which prevent the recruitment and growth of organisms on surfaces, non-toxic coatings allow biofouling to occur and instead rely on the inability of organisms to adhere well to surfaces. Weak adhesion by organisms facilitates their removal through factors such as biotic disturbance or hydrodynamic forces (e.g. Swain et al. 1998; Schultz et al. 1999).

The most effective non-toxic surfaces to date are silicone-based elastomeric coatings. Much of the knowledge of best performing coatings has been derived empirically through extensive laboratory and field testing of emerging coatings (e.g. Swain et al. 1992; Swain \& Schultz, 1996). However, current understanding of the mechanisms by which elastomeric coatings provide easy release is at best incomplete. It has been demonstrated that a variety of factors influences the performance of elastomeric coatings. For example, silicone fluids or the incorporation of oils enhance the performance of elastomeric coatings (e.g. Truby et al. 2000; Kavanagh et al. 2001; 2003; Stein et al. 2003). It is also known that certain factors are important such as surface energy (e.g. Baier et al. 1968; Finlay et al. 2002), coating modulus (e.g. Brady \& Singer, 2000; Singer et al. 2000; Berglin et al. 2003; Chaudhury et al. 2004), frictional slippage (Newby et al. 1995; Newby \& Chaudhury, 1997), and coating thickness (Kohl \& Singer, 1999; Brady \& Singer, 2000). However, the practical importance of the aforementioned factors has not been thoroughly examined in situ using live organisms. It is thus not clear whether such factors are applicable to the release of hardfouling from elastomeric coatings under natural conditions. The primary objective of this study was to examine using live barnacles the effect of coating thickness on the performance of elastomeric coatings. 
The notion that coating thickness is important to performance is based on a fracture mechanics model developed by Kendall (1971). Kendall showed that the force required to pull off a rigid cylinder attached to a thick elastomer is given by

$$
\mathrm{P}_{\mathrm{c}}=\pi \mathrm{a}^{2}\left(\frac{8 E \mathrm{~W}_{\mathrm{a}}}{\pi \mathrm{a}\left(1-v^{2}\right)}\right)^{1 / 2}
$$

where $P_{\mathrm{c}}, E, \mathrm{w}_{\mathrm{a}}$, and $a$ are crack initiation force, elastic modulus, Dupre's work of adhesion between epoxy and elastomer and contact radius, respectively. However, if the contact radius is much larger than the elastomer thickness, i.e. $a \gg h$, where $h$ is the thickness of the elastomer, then the crack initiation force is given by

$$
P_{c}=\pi a^{2}\left(\frac{2 w_{a} K}{h}\right)^{1 / 2}
$$

where $\mathrm{K}$, the bulk modulus of the elastomeric film is related to the elastic modulus by

$$
\mathrm{K}=\mathrm{E} /[3(1-2 v)] \leftarrow
$$

Since $\mathrm{K} \gg \mathrm{E}$, because $v$ approaches 0.5 for an elastomer, a thin coating has a higher $P_{c}$ than a more compliant thick coating.

Indeed, pull-off tests of epoxy bonded to silicone coatings (often called pseudobarnacle tests) have verified the behavior predicted by Kendall's model (Kohl \& Singer, 1999; Brady \& Singer, 2000; Singer et al. 2000). However, the only two published reports to date using live animals (in contrast to pseudobarnacles) failed to find an inverse relationship between coating thickness and pull-off force (Singer et al. 2000; Sun et al. 2004). The absence of a thickness dependence found by Singer et al. (2000) was likely to be due to the fact that most of the barnacle basal plates broke during removal. In this case the mechanics of detachment should not follow Kendall's model, which describes a fracture process where a basal plate would peel from an elastomer.

A proportion of animals growing on silicone coatings have been shown to have atypical basal plate morphology (sometimes referred to as "cupped") that consists of a thick callus of cement present between the calcareous basal plate and the substratum; the basal plate often forms a cup over this thick callus (Watermann et al. 1997; Berglin \& Gatenholm, 2003; Wiegemann \& Watermann, 2003). Moreover, Holm et al. (2005) have shown that the occurrence of the atypical basal plate morphology has both an environmental and a genetic underpinning and that there is a significant interaction between these factors. Sun et al. (2004) suggest that atypical basal plate morphology may form as a result of increased production of adhesive as animals try to maintain contact with a PDMS substratum. In the present study tests were carried out to see if the atypical morphology may be in part related to the effective compliance of the substratum, and therefore, it was predicted that the frequency of the atypical morphology may increase on the thicker, more compliant coatings.

An initial study was conducted to determine which of two commercially available silicones, Sylgard $184^{\mathrm{TM}}$ or a cross-linked polydimethylsiloxane elastomer by Gelest $^{\mathrm{TM}}$, hereafter referred to as PDMSdp125, gave the more effective foul-release surface. After determining that the PDMSdp125 was the more effective of the two, the earlier work with pseudobarnacles was then extended by using live barnacles on PDMSdp125 to investigate the effect of coating thickness on i) the rate of growth and size of individuals, ii) the frequency of atypical basal plate and adult cement morphology, and iii) critical release stress (sometimes referred to as adhesion strength). Attempts were also made to determine whether the critical removal stress differed between animals with typical ("flat") and atypical ("cupped") basal plate and adult cement morphology.

\section{Methods}

\section{Silicone materials}

Sylgard $184^{\mathrm{TM}}$ (Dow Corning Corp.) is a twocomponent, high-temperature-vulcanized (HTV) silicone elastomer. Following the product instructions, the base resin and curing agent provided in two separate containers were thoroughly mixed in a ratio of $10: 1$ by weight and cured at $85^{\circ} \mathrm{C}$ for $2 \mathrm{~h}$. The PDMSdp125 coatings were prepared from a base resin (vinyldimethylsiloxy-terminated polydimethylsiloxane, Gelest ${ }^{\mathrm{TM}}$ catalog DMS-V22, 200 cSt, 9400 gmole $^{-1}(125 \mathrm{dp}), 0.4-0.6 \mathrm{wt} \%$ vinyl) using a crosslinker (25-30\% methylhydrosiloxane-dimethyl-

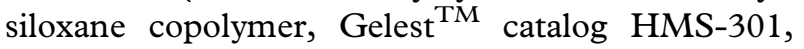
$25-35 \mathrm{cSt}$ ), a catalyst (platinum-divinyltetramethyldisiloxane complex, Gelest ${ }^{\mathrm{TM}}$ catalog SIP6830.0, $3-3.5 \%$ platinum concentration in vinyl terminated polydimethylsiloxane) and a curing control agent (Maleate, from Dow Corning). The mixture was cured at $75^{\circ} \mathrm{C}$ for $1 \mathrm{~h}$.

\section{Coating preparation}

Two sets of coatings were prepared at NRL for barnacle adhesion and removal studies. The first set was 10 slides each with $1 \mathrm{~mm}$ thick coatings of Sylgard $184^{\mathrm{TM}}$ and of PDMSdp125. The second set was PDMSdp125 coatings at thicknesses of $0.1 \mathrm{~mm}$, $0.5 \mathrm{~mm}$ and $2 \mathrm{~mm}$. To achieve the correct thickness, the silicone mixtures were poured into a cast 
consisting of a microscope glass slide at the base and spacers on four sides of fixed height. The surface of the glass slide was coated with a silane coupling agent to promote bonding to the coating. After pouring the mixture, it was carefully covered by a hydrophobic glass slide to constrain the thickness of the mixture during curing; then the cast assembly was secured with six clamps. The assembly was placed in an oven where the mixture cured. After curing, the hydrophobic glass slide was removed. It should be noted that the process of using a hydrophobic glass slide can affect the surface properties of a cross-linked PDMS, and can differ from an air cured PDMS. The coatings were air-cured for several weeks before leaching. Measurements via indentation showed that the cured coatings acted as true elastomeric surfaces, indicating complete curing.

Ten slides of each thickness were sent to Cal Poly for barnacle studies and two slides remained at NRL for pseudobarnacle testing (to be reported in a separate paper). Both sets of coatings were leached in $0.2 \mu \mathrm{m}$ filtered natural sea water for $6 \mathrm{~d}$.

\section{Larval settlement and growth conditions}

Balanus amphitrite cypris larvae were obtained from the Duke University Marine Laboratory. A $500 \mu \mathrm{l}$ drop of seawater containing 20-50 cypris larvae was placed on each treated microscope slide in a covered Petri dish. Cypris larvae were allowed to settle in these conditions for $72 \mathrm{~h}$ at $25^{\circ} \mathrm{C}$ in a constant temperature incubator under a $12 \mathrm{~h}$ light/dark cycle. After that time, each slide was transferred to a separate $100 \mathrm{~mm} \times 20 \mathrm{~mm}$ Petri dish and immersed in $40 \mathrm{ml}$ of natural, $0.2 \mu \mathrm{m}$ filtered seawater. For the pilot study on two different commercially available PDMS formulations, settlement was performed on 28 April 2003. For the coating thickness experiment this was done on two separate occasions: 27 December 2003 and 27 February 2004.

Newly metamorphosed barnacles were fed the unicellular alga Duneliella tertiolecta and the diatom Skeletonema costatum. Nauplius larvae of the brine shrimp, Artemia sp., were added to their diet 2 weeks following settlement. Feeding was done every Monday, Wednesday and Friday, and involved a complete replacement of the seawater and food suspension within each Petri dish. Animals were reared at $25^{\circ} \mathrm{C}$ in a constant temperature incubator under a $12 \mathrm{~h}$ light/dark cycle.

\section{Growth of basal plate}

Barnacles growing on 5 slides of each thickness were monitored monthly from 31 December 2003 to 31 March 2004 to determine if there were any differences in growth rate of the basal plates as a function of coating thickness. Photography was performed using a Canon ${ }^{\mathrm{TM}}$ EOS 10D digital camera attached to an Olympus ${ }^{\mathrm{TM}}$ SZX12 dissecting microscope. The basal plates of the developing barnacles were photographed through the transparent substratum, and the area of the basal plate was calculated using NIH's ImageJ image analysis software. Basal plate areas were compared by analysing data from 31 March 2005 in one- and two-factor ANOVAs.

\section{Shear testing}

The shear test apparatus consisted of an IMADA ${ }^{\mathrm{TM}}$ AXT 70 digital force gauge $(2 \mathrm{~kg})$ mounted on an IMADA $^{\mathrm{TM}}$ SV-5 motorised stand. The force gauge was attached to a motorised stand that moved a shearing head parallel to the coating surface at an average speed of approximately $67 \mathrm{um} \mathrm{s}^{-1}$. The glass slides were clamped into a custom-built Plexiglas chamber that allowed complete submersion of coatings during release tests. Prior to each test, basal plates were photographed using a Canon ${ }^{\mathrm{TM}}$ EOS 10D digital camera attached to an Olympus ${ }^{\mathrm{TM}}$ SZX12 dissecting microscope, and areas were calculated using NIH's ImageJ. As the coating surface was flat, barnacle adhesive was assumed to be in contact with the substratum over the entire basal plate surface; therefore the size of the basal plate was measured to determine area. Only barnacles with a diameter $>3 \mathrm{~mm}$ were shear tested. The force at which the barnacle detached from the coating, the maximum force measured, is hereafter called the critical removal force; the critical removal stress is obtained by dividing the critical removal force by the measured basal area. The shear test was discarded in cases where any fraction of the basal plate remained attached to the surface. Procedures for performing shear tests differed from ASTM D 5618 in that the shear force was applied by an automated test stand and the barnacle release was performed in water. In June 2003, shear tests were performed on the first set of PDMSdp125 and Sylgard $184^{\mathrm{TM}}$ (1 mm thick) coatings. The second set $(0.2,0.5$ and $2 \mathrm{~mm}$ thick) of coatings was shear tested on two occasions: mid-February and mid-June 2004. Data from shear testing satisfied the assumptions for an ANOVA, and were analysed using oneand two-factor ANOVAs and Fisher's PLSD post-hoc tests.

Photographs were also used to determine the morphology of the barnacle basal plates. The atypical or altered cement produced by barnacles growing on silicone surfaces could be observed visually as a white mass that obscured the radial structures characteristic of the barnacle's basal plate (Berglin \& Gatenholm, 2003; Wiegemann \& Watermann, 2003). Barnacles exhibiting any "clouding" of the 
basal plate when viewed from below were designated as having the atypical or "cupped" morphology, with all others being designated "flat". The rate of occurrence of atypical basal plates was determined for each slide, and compared via a one-way ANOVA.

\section{Results}

Critical removal stress for PDMSdp125 vs Sylgard $184^{\mathrm{TM}}$

Only $44 \%$ of the barnacles removed from Sylgard 184 exhibited complete release from the surface, without leaving all or part of the basal plate on the surface of the coating. By contrast, $87 \%$ of the barnacles removed from PDMSdp125 exhibited complete release from the surface. Mean critical removal stresses for barnacles removed from $1 \mathrm{~mm}$ thick coatings of Sylgard $184^{\mathrm{TM}}$ and PDMSdp125 were $0.10 \pm 0.02 \mathrm{MPa}$ and $0.069 \pm 0.007 \mathrm{MPa}$, respectively; although technically not significant (one-factor ANOVA; $n=21, \mathrm{~F}=4.11, p=0.057$ ) the $p$-value was only marginally higher than a 0.050 critical value.

\section{Occurrence of atypical basal plate and adult cement morphology}

The formation of atypical basal plates and adult cement were observed on all coatings tested (see Figure 1). The proportion of individuals with the atypical morphology was significantly different among coatings of different thickness (one-factor ANOVA; $n=15, \mathrm{~F}=3.9, p<0.05$ ) (Figure 2). The lowest frequency of occurrence was on the $0.5 \mathrm{~mm}$ coating. The atypical morphology was observed in essentially equal frequency on the thinnest $(0.1 \mathrm{~mm})$ and thickest $(2.0 \mathrm{~mm})$ samples. Many of the individuals displayed an "intermediate" morphology; that is, the basal plate had the cupped appearance in the centre and a flat morphology closer to the perimeter (Figure 1C). The reverse situation was not observed.

\section{Growth rate and size as a function of coating thickness}

Growth rate, as measured by the increase in basal plate area, did not differ among coating thicknesses (see Figure 3). Likewise, the areas of basal plates on the three thicknesses were statistically indistinguishable throughout the three months of the experiment (one-factor ANOVA; $n=13, \mathrm{~F}=0.52, p=0.61$ ) (Figure 4A). The size of individuals with "cupped" basal plates was not significantly different from individuals with "flat" basal plates (two-factor ANOVA; $n=37$, thickness $\mathrm{F}=1.23, p=0.30$; morphology $\mathrm{F}=0.04, p=0.83$ ) (Figure $4 \mathrm{~B}$ ).
Critical removal stress as a function of coating thickness

Critical removal stress was significantly different and inversely proportional to coating thickness (one-factor ANOVA; $n=44, \mathrm{~F}=6.681, p=0.0031$ ) (Figure 5). The average critical removal stress was $0.093 \pm 0.008$ $\mathrm{MPa}, 0.074 \pm 0.005 \mathrm{MPa}$, and $0.055 \pm 0.006 \mathrm{MPa}$ on $0.1 \mathrm{~mm}, 0.5 \mathrm{~mm}$, and $2 \mathrm{~mm}$ thick coatings, respectively. A post hoc test showed a significant difference in critical removal stress between $2 \mathrm{~mm}$ and both $0.5 \mathrm{~mm}$ and $0.1 \mathrm{~mm}$, but not between $0.1 \mathrm{~mm}$ and $0.5 \mathrm{~mm}$ (Figure 5A). The data also show a lower critical removal force for barnacles with an atypical basal plate than for barnacles with a typical basal plate (two-factor ANOVA: $n=44$, thickness, $\mathrm{F}=7.437, p=0.0019$; basal plate morphology, $\mathrm{F}=\leftarrow$ $4.182, p=0.0478$; interaction, $\mathrm{F}=0.478, p=0.6338$ ) (Figure 5B).

\section{Discussion}

Growth rate and size as a function of coating thickness

The hypothesis that the growth rate of the basal plate might differ significantly among coating thickness was not supported (Figures 3 and 4). However, using the basal plate area as a proxy for growth does not take into account the actual mass of the animal. Thus differences among barnacles growing on different thicknesses may not have been detected.

\section{Occurrence of atypical basal plate and adult cement morphology}

The appearance of atypical basal plates and adult cement has been observed when barnacles grow on silicone coatings (Watermann et al. 1997, Berglin \& Gatenholm, 2003; Wiegemann \& Watermann, 2003; Holm et al. 2005; Kavanagh \& Swain, personal communication) (Figure 1). Individuals exhibiting the atypical morphology were observed to synthesise a thick, paste-like cement that was granular in nature, which was similar to the atypical morphology reported by Berglin and Gatenholm (2003). The exact mechanism by which silicone coatings disrupt the typical process of basal plate growth and adult cement formation is not understood. Sun et al. (2004) suggest that atypical basal plate morphology may form as a result of increased production of adhesive as animals try to maintain contact with a PDMS substratum. Berglin and Gatenholm (2003) showed using electron probe microanalysis and infrared spectroscopy that calcium was incorporated as calcite in barnacles with typical basal plate and adult cement morphology grown on polymethlymethacrylate; in contrast, no 

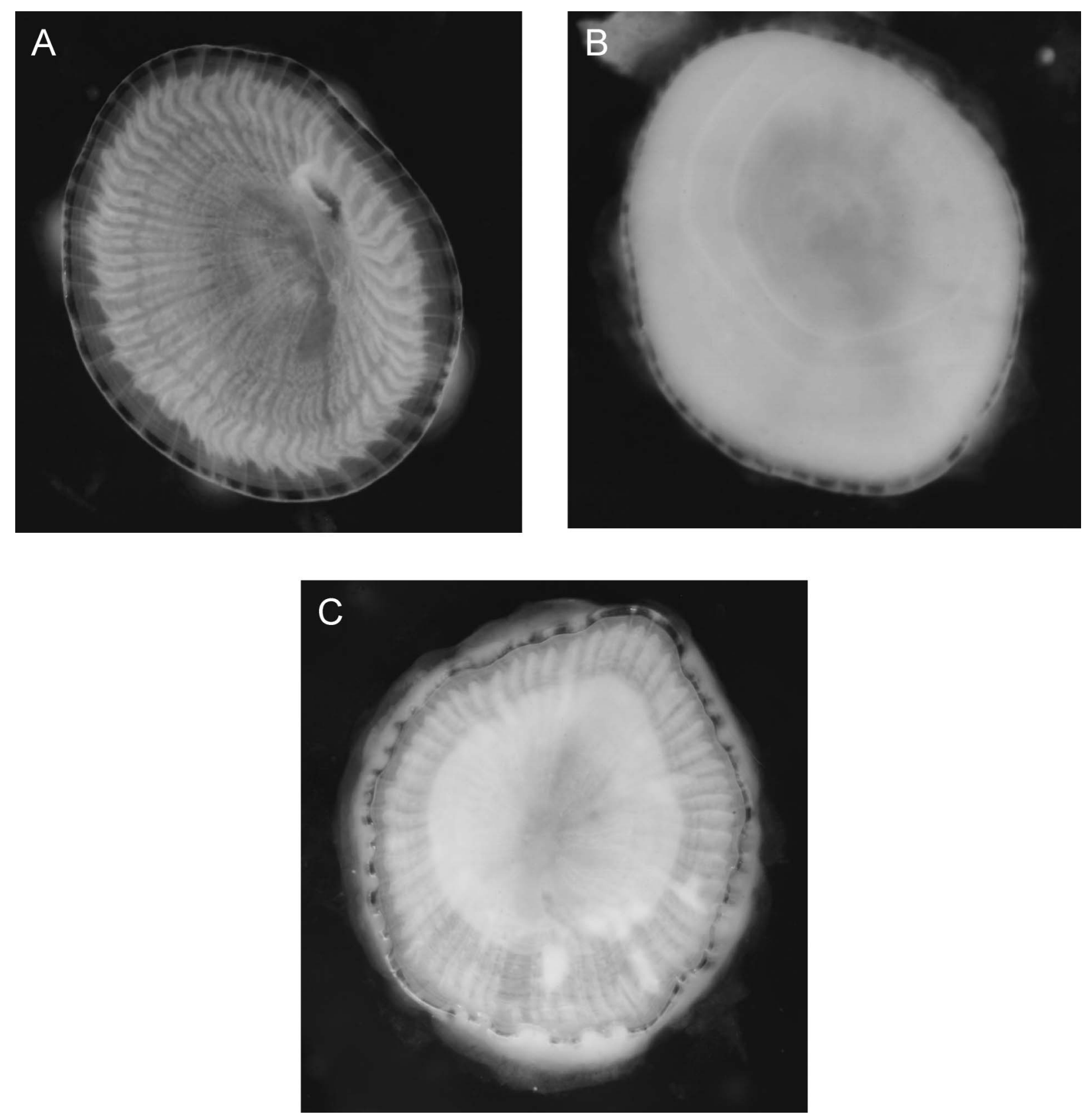

Figure 1. Examples of the various morphologies of a barnacle basal plate grown on an elastomeric surface. A=typical or " flat" morphology; $\mathrm{B}=$ atypical or "cupped" morphology; $\mathrm{C}=$ transitional basal plate exhibiting both "cupped" and "flat" characteristics.

calcium could be detected in the adult cement of animals with the atypical morphology grown on a polydimethylsiloxane (silicone) coating. In the same study the authors did not report on the frequency of occurrence of the atypical morphology in their experiments. The present results showed that some individuals grown on silicone coatings exhibit the typical basal plate and adult cement morphology. It was also observed that individuals may initially have an atypical ("cupped") morphology, but then change to the typical ("flat") morphology as the animal grows. Holm et al. (2005) have demonstrated genetic underpinnings that at least in part determine the frequency of occurrence of the atypical morphology. In their experiments different genetic families of the barnacle $B$. amphitrite exhibited different rates of occurrence of the atypical morphology when grown on the same silicone coatings. That a monotonic relationship between coating thickness and occurrence of the atypical morphology was not found suggests that coating thickness (and therefore effective compliance) does not directly influence the frequency of occurrence of the atypical morphology (Figure 2). 


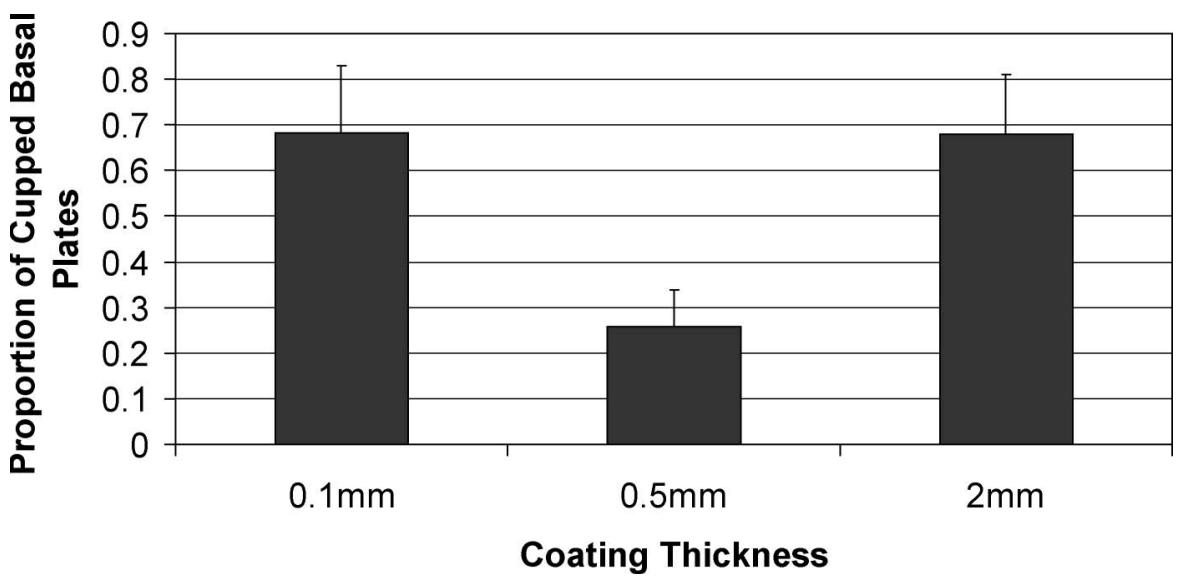

Figure 2. The proportion of atypical, or "cupped" basal plates occurring on three different thicknesses of PDMS.

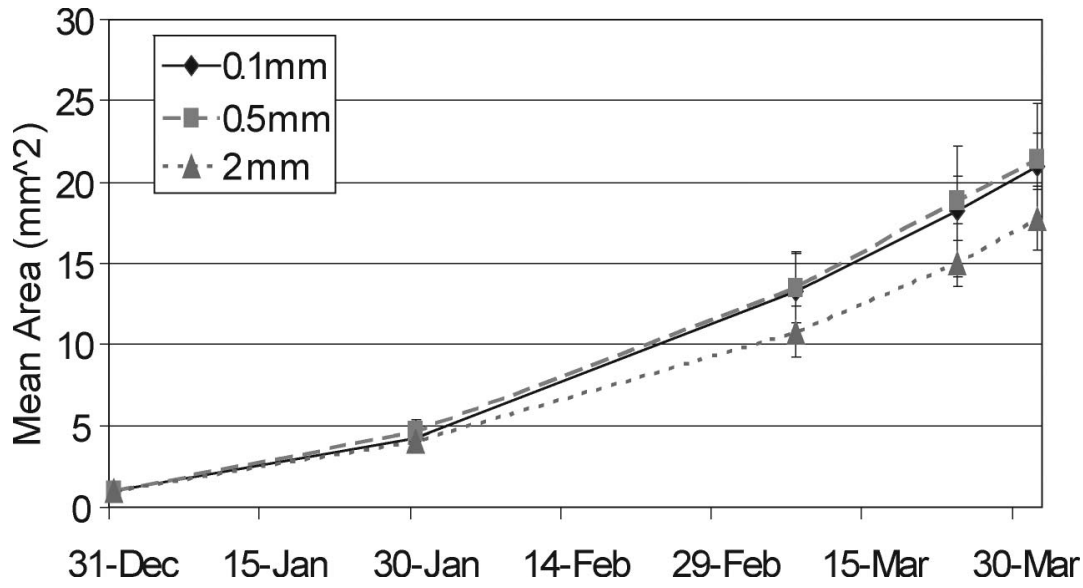

Figure 3. Growth rate of barnacle basal plates grown on three thicknesses of PDMS: $0.1 \mathrm{~mm}, 0.5 \mathrm{~mm}$, and $2 \mathrm{~mm}$.

\section{Critical removal stress as a function of coating thickness}

The results showed that critical removal force decreased as a function of coating thickness, although not as $1 / h^{1 / 2}$, where $h$ is coating thickness, as predicted by Kendall (1971) for pull-off removal. There are several reasons why this particular powerlaw behaviour might not apply to shear of barnacles. First, no theoretical model of shear currently exists that predicts a $1 / h^{1 / 2}$ behaviour. Secondly, the deviation could be an experimental artifact, e.g. due to the application of non-shearing forces (e.g. torque). In addition, Chaudhury has calculated the thickness dependence of the shear removal stress for both solid and flexible plates attached to elastomeric coatings (Chaudhury, personal communication, 2005). He found that the thickness dependence weakened as the flexibility of the plate decreased to that of the coating. The present results also show that the removal stress was lower for barnacles with atypical basal plates than for barnacles with typical basal plates (Figure 5B). These data suggest that the functionality of the adhesive has been compromised in some capacity, which is consistent with the observations and data of Berglin and Gatenholm (2003) and Sun et al. (2004).

\section{Basal plate breakage during removal in shear}

It is known that on non-easy release surfaces the basal plates of barnacles will often fracture as animals are dislodged. If the integrity of the basal plate is compromised during removal, then it is likely that the adhesion between the surface and the barnacle cement is so great that the basal plate cannot support the forces needed to dislodge the animal. As the animal grows, the basal plate structural integrity increases (e.g. Berglin et al. 2001). Berglin et al. (2001) showed a gradual transition during barnacle growth in failure mode, viz. i) the smallest barnacles showed a total cohesive failure leaving the entire basal plate on the surface, ii) as the animals grew they shifted to a mixed failure mode where a portion of the basal plate is removed (i.e. breaking of the basal plate), and iii) complete removal of the barnacle 

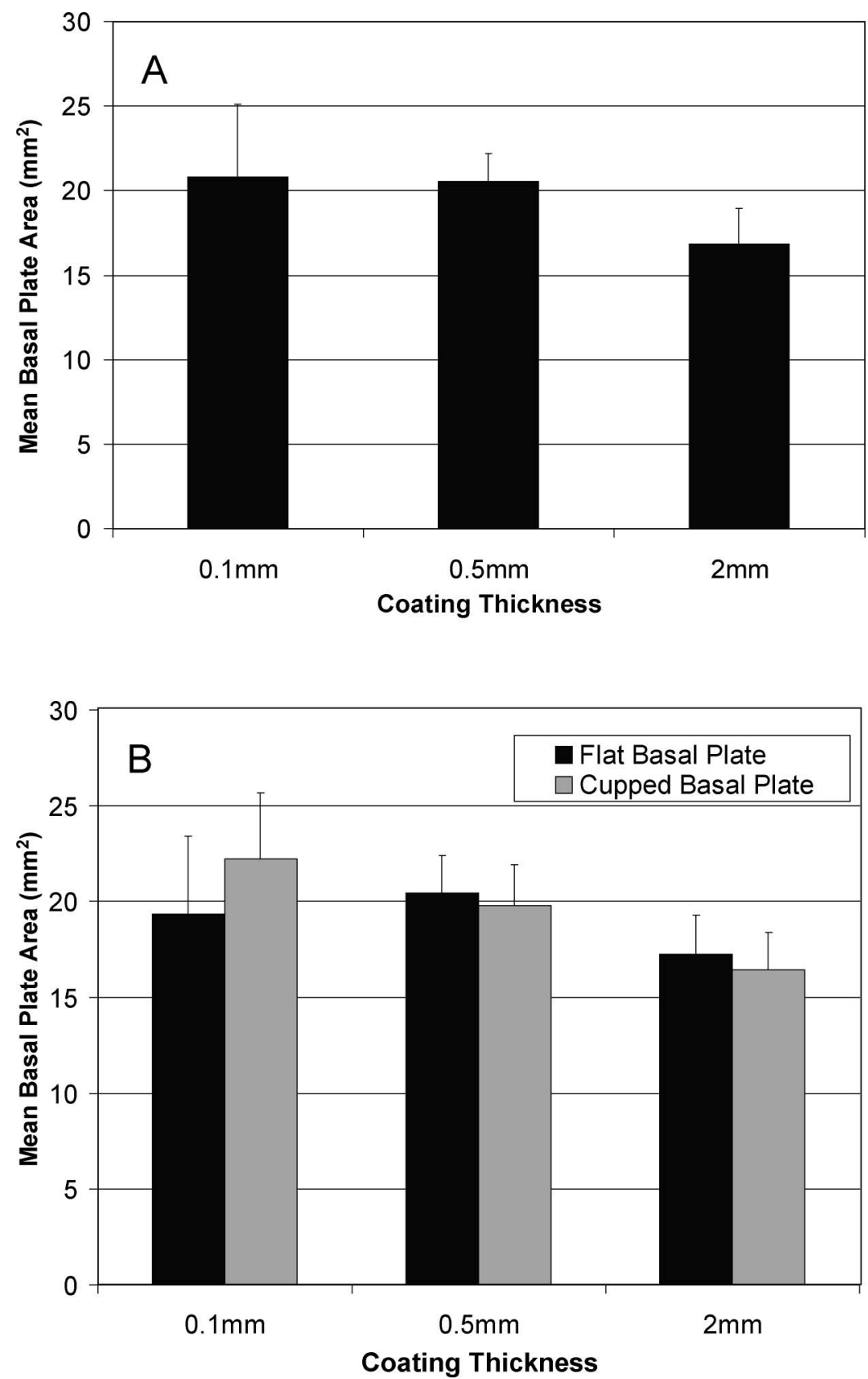

Figure 4. Mean area of the basal plates of barnacles grown on three thicknesses of PDMS, as measured during shear testing. $\mathrm{A}=\mathrm{mean}$ area for all barnacles on each of three thicknesses; $\mathrm{B}=$ mean area of barnacles exhibiting the typical ("flat") basal plate and the atypical (“cupped") basal plate.

including the entire basal plate, indicating failure of the adhesive bond to the surface. This transition, which they suggest is a measure of the balance between the cohesive strength of the barnacle basal plate and the adhesion bond to the surface, occurs earlier (i.e. for smaller barnacles) on better performing foul-release surfaces. Earlier observations of Singer et al. (2000) showed that the barnacle $B$. improvisus often broke during removal in tensile from Sylgard $184^{\mathrm{TM}}$. In the present study with B. amphitrite a similar situation was observed; only $44 \%$ of the barnacles grown on Sylgard $184^{\mathrm{TM}}$ were removed from the surface without cohesive failure, whereas animals of the same size grown on PDMSdp125 showed $87 \%$ complete removal. In the coating thickness experiment using only PDMSdp125 coatings total cohesive failure was never observed and greater than $90 \%$ of the animals showed failure of the adhesive bond to the surface (i.e. complete basal plate removal). These data clearly demonstrate i) that not all silicone coatings are easy release, and ii) that a pure PDMS such as PDMSdp125 can be easy release without additives such as oils. 

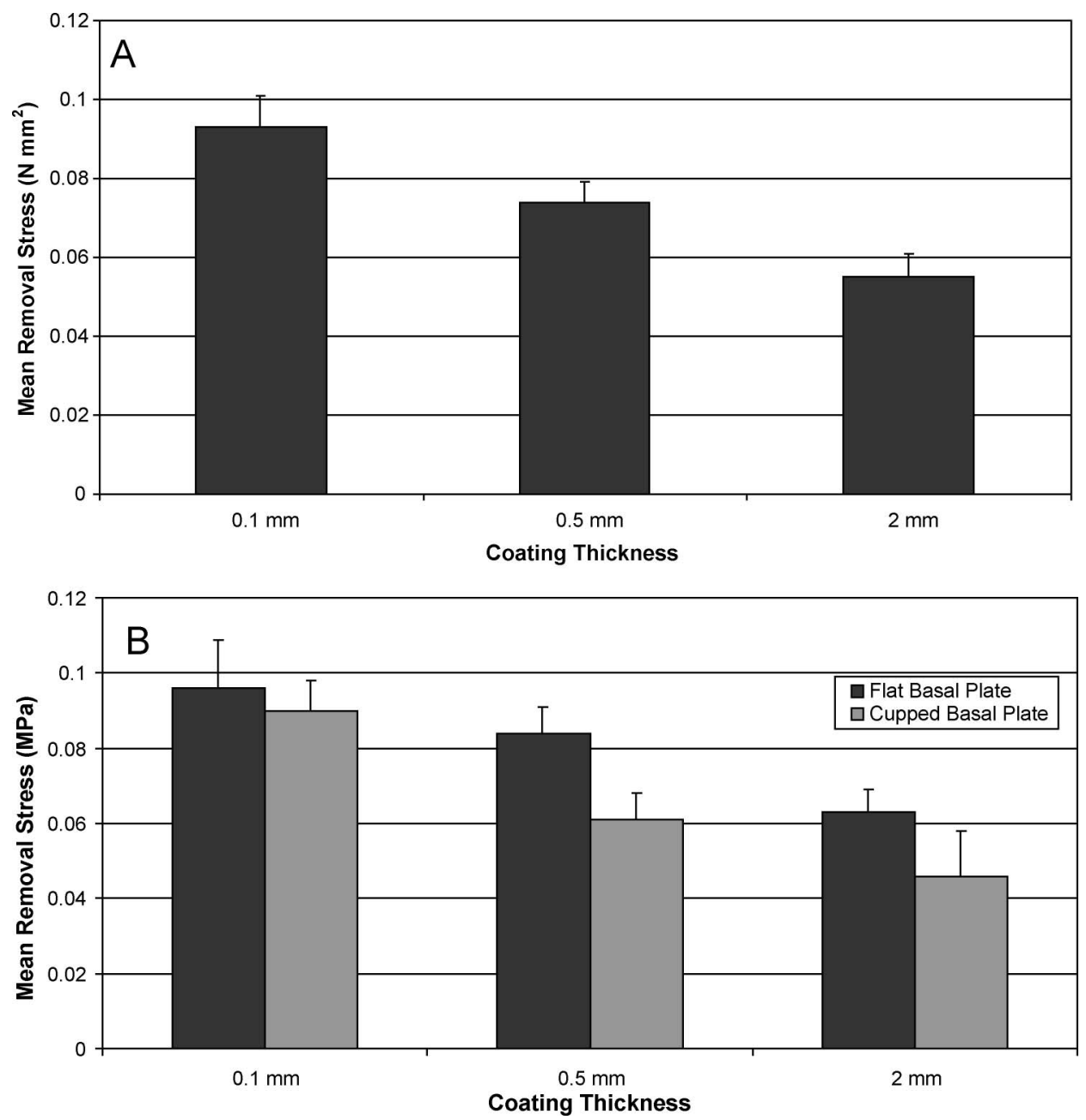

Figure 5. Mean critical removal stress of barnacles removed in shear from three thicknesses of PDMS. A= overall mean critical removal stress; $\mathrm{B}=$ mean critical removal stress of barnacles exhibiting the two different basal plate morphologies: typical ("flat") and atypical ("cupped").

\section{Summary}

No relationship was found between coating thickness and the rate of growth or the size of barnacle basal plates. There was additionally no discernable relationship between coating thickness and the occurrence of atypical basal plate and adult cement morphology (i.e. "cupped" vs "flat"). Critical release stress qualitatively obeyed fracture mechanics model, i.e. release force decreased with increasing thickness in confinement regime. Indeed, critical removal stress was significantly lower on $2 \mathrm{~mm}$ coatings than on either $0.1 \mathrm{~mm}$ or $0.5 \mathrm{~mm}$ coatings. Moreover, critical removal stress was lower for barnacles with atypical basal plates than for barnacles with typical basal plates. Although $2 \mathrm{~mm}$ is thicker than is practical for most commercial coatings, the data demonstrate that coating thickness is an important parameter governing removal of barnacles from elastomeric coatings; coating thickness should be considered when optimising the design of elastomeric foul-release surfaces.

\section{Acknowledgements}

We thank Dan Rittschoff and Beatriz Orihuela-Diaz, both of Duke University, for providing us with barnacle cypris larvae, and Emily Wilson, Ruth Armour, Danielle Castle, and Lisa Needles for their assistance with the culture of juvenile barnacles at Cal Poly. The US Office of Naval Research is gratefully acknowledged for financial support (Grants no. N00014-02-0935 to DEW; N0001404-WX-2-0311 to ILS). Jongsoo Kim gratefully acknowledges funding support of Lehigh University and ONR (2002-2004) and North Dakota State University (2004-2005). We also thank two anonymous reviewers for their helpful comments and suggestions. 


\section{References}

Anonymous. 1997. ASTM D 5618-94. Standard test method for measurement of barnacle adhesion strength in shear. Annual book of ASTM standards Vol. 06.02. West Conshohocken, PA: American Society for Testing and Materials.

Baier RE, Shafrin EG, Zisman WA. 1968. Adhesion: mechanisms that assist or impede it. Science 162:1360-1368.

Berglin M, Gatenholm P. 2003. The barnacle adhesive plaque: morphological and chemical differences as a response to substrate properties. Colloids Surf B: Biointerfaces 28:107117.

Berglin M, Lonn N, Gatenholm P. 2003. Coating modulus and barnacle bioadhesion. Biofouling 19:63-69.

Berglin M, Larsson A, Jonsson PR, Gatenholm P. 2001. The adhesion of the barnacle, Balanus improvisus, to poly(dimethylsiloxane) fouling-release coatings and poly(methylmethacrylate) panels: the effect of barnacle size on strength and failure mode. J Adhesion Sci Technol 15:1485-1502.

Brady RF, Singer IL. 2000. Mechanical factors favoring release from fouling release coatings. Biofouling 15:73-81.

Chaudhury MK, Finlay JA, Chung JY, Callow ME, Callow JA. 2004. The influence of elastic modulus and thickness on the release of the soft-fouling green alga Ulva linza (syn. Enteromorpha linza) from poly(dimethylsiloxane) (PDMS) model networks. Biofouling 21:41-48.

Finlay JA, Callow ME, Ista LK, Lopez GP, Callow JA. 2002. The influence of surface wettability on the adhesion strength of settled spores of the green alga Enteromorpha and the diatom Amphora. Integr Comp Biol 42:1116-1122.

Holm ER, Orihuela B, Kavanagh CJ, Rittschof D. 2005. Variation among families for characteristics of the adhesive plaque in the barnacle Balanus amphitrite. Biofouling 21:121-126.

Kavanagh CJ, Swain GW, Schultz MP, Stein J, Truby K, Darkangelo-Wood C. 2001. Variation in adhesion strength of Balanus eburneus, Crassostrea virginica and Hydroides dianthus to fouling release coatings. Biofouling 17:155-167.

Kavanagh CJ, Swain GW, Kovach BS, Stein J, Darkangelo-Wood C, Truby K, Holm ER, Monetemarano J, Meyer A, Wiebe D. 2003. The effects of silicone fluid additives and silicone elastomer matrices on barnacle adhesion strength. Biofouling 19:381-390.

Kendall K. 1971. The adhesion and surface energy of elastic solids. J Physics D: Appl Physics 4:1186-1195.

Kohl JG, Singer IL. 1999. Pull-off behavior of epoxy bonded to silicone duplex coatings. Prog Organic Coatings 36:15-20.

Newby BZ, Chaudhury MK. 1997. Effect of interfacial slippage on viscoelastic adhesion. Langmuir 13:1805-1809.
Newby BZ, Chaudhury MK, Brown HR. 1995. Macroscopic evidence of the effect of interfacial slippage on adhesion. Science 269:1407-1409.

Schultz MP, Kavanagh CJ, Swain GW. 1999. Hydrodynamic forces on barnacles: implications on detachment from fouling release surfaces. Biofouling 13:323-335.

Singer IL, Kohl JG, Patterson M. 2000. Mechanical aspects of silicone coating for hard foulant control. Biofouling 16:301309.

Stein JK, Truby K, Darkangelo-Wood C, Stein J, Gardner M, Swain G, Kavanagh C, Kovach B, Schultz M, Wiebe D, Holm E, Montemarano J, Wendt D, Smith C, Meyer A. 2003. Silicone foul release coatings: effect of the interaction of oil and coating functionalities on the magnitude of macrofouling attachment strengths. Biofouling 19 (Suppl):71-82.

Sun Y, Guo S, Walker GC, Kavanagh CJ, Swain GW. 2004. Surface elastic modulus of barnacle adhesive and release characteristics from silicone surfaces. Biofouling 20:279-289.

Swain GW. 2004. In search of the perfect ship hull coating. Plenary Presentation, 12th International Congress on Marine Corrosion and Fouling, University of Southampton, Southampton, UK.

Swain GW, Schultz MP. 1996. The testing and evaluation of nontoxic antifouling coatings. Biofouling 10:187-197.

Swain GW, Nelson WG, Preedeenkanit S. 1998. The influence of biofouling adhesion and biotic disturbance on the development of fouling communities on non-toxic surfaces. Biofouling 12:257-269.

Swain GW, Griffith JR, Bultman JD, Vincent HL. 1992. The use of barnacle adhesion measurement for the field evaluation of non-toxic foul release surfaces. Biofouling 6:105-114.

Truby K, Wood C, Stein J, Cella J, Carpenter J, Kavanagh C, Swain G, Wiebe D, Lapota D, Meyer A, Holm E, Wendt D, Smith C, Montemarano J. 2000. Evaluation of the performance enhancement of silicone biofouling-release coatings by oil incorporation. Biofouling 15:141-150.

Walker I. 1998. Non-toxic fouling control systems. Pitture Vernici Eur 13:17-22.

Watermann B, Berger HD, Sonnichsen H, Willemsen P. 1997. Performance and effectiveness of non-stick coatings in seawater. Biofouling 11:101-118.

Wiegemann M, Watermann B. 2003. Peculiarities of barnacle adhesive cured on non-stick surfaces. J Adhesion Sci Technol $17: 1957-1977$. 